\title{
Consumer experiences in fitting rooms in SPA stores
}

\author{
So Jung Yun, Hye In Jung and Ho Jung Choo*
}

\author{
*Correspondence: \\ chooho@snu.ac.kr \\ Department of Textiles, \\ Merchandising and Fashion \\ Design, Seoul National \\ University, 1 Gwanak-ro, \\ Gwanak-gu, Seoul 151-742 \\ Republic of Korea
}

\begin{abstract}
This study explores fashion consumers' experiences and behaviors in the fitting room, and tries to understand what their behavior means. The research design is based on the grounded theory and the research question is "What do fashion consumers experience in fitting rooms in SPA stores?" Customers carry out four major actions when using fitting rooms in SPA stores. Firstly, they inspect the physical and aesthetic aspects of the clothing items. Secondly, purchase decision of an item in consideration of its function and price, and the advice of the people who accompany them or friends via social networking sites are processed. Thirdly, consumers are simply enjoying trying them on as a form of entertainment. Fourthly, consumers explore other shopper' choices when they are waiting in long line to use the fitting room. Then, "enjoying trying on clothes" and the conditions affect it were identified. The pleasure of trying on clothes can be experienced more readily when the reason for shopping is simply leisure, or when the spacious store, wide variety of products, the liberal and independent atmosphere in the fitting room are provided. In this context, participants regarded advice from sales assistants as rather burdensome.
\end{abstract}

Keywords: Fitting room, Dressing room, Try on, Leisure shopping, Hedonic shopping

\section{Introduction}

Specialty store retailers of private label apparel (SPAs) operate large scaled stores that present a different atmosphere than conventional department stores. Large apparel shops located in city centers offer consumers the comfort and pleasure of shopping, with layout design changing as swiftly as the inventory turnover, which includes a wide variety of products. The shopping environment created by SPA stores is considered the key competitive advantage of an SPA brand (Kim and Yang 2015).

Above all, SPA brands' fitting rooms, where customers can freely try on any number of items, are a special attraction for consumers; these rooms provide a different environment than earlier shopping experiences. SPA brands' fitting rooms are multi-numbered private rooms, which allow customers to try clothes on leisurely without feeling conscious of other people, as they might in fashion retail stores with fewer fitting rooms. In addition, SPA stores provide an atmosphere in which consumers can try on items without feeling burdensome, because staffs at SPA brands' fitting room simply check the items that customers return after trying them on in the fitting rooms; they usually do

(c) 2015 Yun et al. This article is distributed under the terms of the Creative Commons Attribution 4.0 International License (http:// creativecommons.org/licenses/by/4.0/), which permits unrestricted use, distribution, and reproduction in any medium, provided you give appropriate credit to the original author(s) and the source, provide a link to the Creative Commons license, and indicate if changes were made. 
not offer advice or recommend purchases to their customers, as do salespersons in conventional apparel stores.

One study (Kwon 2006) noted that shopping activities largely depend on a store's atmosphere, and it is only natural that consumers experiencing new environments rapidly change their activities such as entering the stores, looking around and searching, selecting items, and deciding what to buy. In the SPA brand stores with this more comfortable fitting room, customers presumably explore the store more actively, choose to try on items more frequently, and have an increased number of various emotional and cognitive experiences, along with a wide variety of judgmental experiences. Even people waiting in long lines to use the fitting room express pleasure at their expectations, rather than frustration at having to wait.

However, only a handful of studies have investigated customers' behavior in independent fitting rooms in large fashion stores. A fitting room is an important place where consumers can inspect whether clothes fit them and match their taste before deciding to buy them. A fitting room is also a space where social, aesthetic, and psychological experiences can occur. This study explores personal and psychological experiences in independent fitting rooms in SPA brand stores.

\section{Literature review}

\section{Fitting room and trying on}

Fitting rooms are places where customers' inspection for purchase decision-making takes place, and they play a vital role at fashion retail stores; however, there have not been enough studies done regarding the fitting rooms in the fashion marketing field. Previous studies on fitting rooms in fashion retail stores focused mainly on the physical environment of the fitting room, such as size, color, lighting, and mirrors, as well as consumer's responses to these elements (Kim and Kim 2015; Song et al. 2013). Baumstarck and Park (2010) identified the effect of fitting room lighting on consumers' emotional evaluation; Kang (2015)'s study focused on consumers' psychological experiences in fitting rooms, and reported that distorting the fitting room environment with mirrors and lighting can affect customers' satisfaction with their self-appearance, thus influencing their purchase behavior. Meanwhile, Moody et al. (2010), instead of focusing on fitting room environment, performed psychological research on the relationship between personality factors and clothing style preferences in the process of trying on apparel items.

\section{Evaluating clothing items by trying on}

Fitting rooms are also termed changing rooms or dressing rooms; they are defined as store spaces in which consumers try on items of clothing in order to check and evaluate the elements of the clothing items before making a purchase (Kang 2015; Kim 1992). That is; the most fundamental goal of using the fitting room is to inspect and evaluate the clothing item by trying it on.

Siben (1991) and Yoon and Kijewski (1997) note that the assessment of clothing quality is related to customer satisfaction. Brown and Rice (1998) suggest that physical and behavioral factors influence customers' evaluation of clothing quality; physical factors include unchangeable characteristics such as product designs, materials, fabric construction, and finishing methods. Behavioral features are divided into the functional and 
aesthetic aspects of the clothing. The functional element is the clothing item's durability and its appropriateness for a specific situation, while the aesthetic factor is comprised of sensual, emotional, or cognitive aspects.

\section{Consulting with others}

People tend to make decisions based on others' judgments. When people make decisions, they are significantly influenced by group norms, which are set based on other people's judgments (Bertrandias and Goldsmith 2006). When the situation is unclear or it is difficult to make an accurate judgment, and when it is important to address a situation, people are more likely to depend on other people's judgment (Cialdini et al. 1991). In addition, people tend to rely more on others' judgments when they believe the other people are professionals or have more expertise regarding the situation (Cialdini and Trost 1998).

In fashion retail stores, consumers' evaluation is influenced by salesperson or those who accompany them (Park and Park 1995; Choi and Chung 2008). Among them, salespersons have strong impact on consumers' purchase decisions by providing persuasive information on the clothing (Kotler and Keller 2009). However, with regard to the necessity and significance of salespersons, individual customers have different opinions based on their personal preferences (Lee et al. 1994); one of the recent studies pointed out that SPA brand stores lack personal assistance from salespersons (Kim et al. 2013).

\section{Leisure shopping}

The fact that consumers experience pleasure or enjoyment from shopping itself has been acknowledged and studied using terms such as "leisure shopping" or "hedonic shopping" (Babin et al. 1994; Howard 2007; Bäckström 2011). In an exploratory study of hedonic shoppers' shopping experiences, Bäckström (2011) discerned three themes of leisure shopping experience: ambition to find desirable objects; aesthetic enjoyment and stimulation of senses from just experiencing stores, products, and people at a shopping mall; and joy of the social interaction with friends or family members during leisure shopping. Regarding Unger and Keman (1983), the more they notice entertaining factors, the more they indulge in shopping.

Fiore and Kimle (1997) noted that the interaction between consumers' bodies and apparel items could complicate the decision-making process; the interaction arouses sensory, emotional, and cognitive responses. They observed that consumers enjoy entire components of the aesthetic experience via this interaction. In this context, "trying on clothes" or "fitting" can be also pleasurable for consumers rather than cumbersome.

This study explores fashion consumers' emotional experiences and behavior in the fitting room, and determines what their behavior means. The research design is based on grounded theory and the research question is "What do fashion consumers experience in fitting rooms in SPA stores?"

\section{Method}

\section{Grounded theory}

This study adopted grounded theory as research methodology because this approach is helpful to explore new environment and social phenomena for which there are only a 
limited number of previous studies. The grounded theory of Strauss and Corbin (1997) is a qualitative research method that aims to derive a final theory based on systematically gathered and analyzed data. Instead of intuitively devising a theory, a researcher expects to yield one from data obtained on-site. This approach is efficient for vividly depicting a direct experience, which can be difficult to explain using a quantitative research approach, observing interactions with other individuals, or determining the social implications of behavior.

Data collection is a very important step in grounded theory. Using theoretical sampling, the researcher intentionally selects participants suitable for the research topic and mostly gathers data through simultaneously conducting in-depth interviews, data collection, and analysis. Based on the theoretical concept that emerges while performing such analysis, the researcher decides from whom to obtain the second round data collection. The term saturation describes when the researcher decides that he or she has collected enough data by repeating the process. Once saturation occurs, sampling is complete. The data gathered so far are analyzed using methods such as constant comparison, open coding, axis coding, selective coding, process coding, and categorizing (Yoo et al. 2012).

\section{Research participants}

In order to gather real life data on fashion consumers' experiences in the fitting room, the researcher conducted in-depth interviews and directly observed participants by accompanying them when they shopped. To select participants suitable for the research goal, eight young women who enjoy shopping for SPA brands were recruited. As a first round of data collection, four of the participants were recruited by snowball sampling method, and they participated in an interview at a SPA store in the participant's preferred area. After the first round of data collection, open coding analysis was briefly performed. Considering that mostly university student women in their 20 s were recruited for the first round of data collection, women in their 30s and more hedonic shoppers were included in the second round. The other four participants were recruited on site at a big shopping mall "Times Square" where SPA brand stores are concentrated in Seoul. The researcher accompanied the subjects while shopping between November 22 and December 7, 2013. All the participants are Korean, and all the shopping mall was located in Seoul, South Korea. Table 1 outlines the characteristics of the eight participants and the results of observation.

\section{Data collection}

The researcher conducted a brief pre-interview with each participant prior to accompanying her in order to find out her personal details and the usual frequency with which she shopped. The participants were required to shop a store at least $15 \mathrm{~min}$ in order to capture participants' full shopping experience from searching, selecting items, trying them on in a fitting room, to purchasing items, and the average shopping duration at a store was $36 \mathrm{~min}$. The researcher observed the participant's movement within the store, the items she selected, the time she spent in the fitting room, and her behavior after leaving the fitting room. Afterwards, the researcher conducted an in-depth interview for around 30-50 $\mathrm{min}$. In order to induce free responses from the participants, the questionnaire content in Table 2 was given appropriately in the simplest form, and sample 
Table 1 Participants' characteristics and results of observation

\begin{tabular}{|c|c|c|c|c|c|c|c|}
\hline Participant & Age & Occupation & Store & $\begin{array}{l}\text { Shopping } \\
\text { time }\end{array}$ & $\begin{array}{l}\text { Length of } \\
\text { stay in fitting } \\
\text { room (min) }\end{array}$ & $\begin{array}{l}\text { No. of items } \\
\text { tried on }\end{array}$ & $\begin{array}{l}\text { No. of items } \\
\text { purchased }\end{array}$ \\
\hline A & 26 & Student & $\begin{array}{l}\text { Top10 } \\
\text { (Gangnam } \\
\text { station) }\end{array}$ & $11: 30-12: 10$ & 10 & 4 items & 2 items \\
\hline B & 26 & Student & $\begin{array}{l}8 \mathrm{~s} \text { (Gangnam } \\
\text { st.) }\end{array}$ & $16: 00-16: 38$ & 12 & 4 items & 0 items \\
\hline C & 26 & Student & $\begin{array}{l}\text { Uniqlo (Gang- } \\
\text { nam st.) }\end{array}$ & 18:40-19:15 & 15 & 6 items & 2 items \\
\hline D & 26 & Official & $\begin{array}{l}8 \text { s (D-cube } \\
\text { city) }\end{array}$ & $18: 45-19: 20$ & 11 & 5 items & 0 items \\
\hline E & 22 & $\begin{array}{l}\text { Company } \\
\text { employee }\end{array}$ & $\begin{array}{l}8 \mathrm{~s} \text { (Times } \\
\text { square) }\end{array}$ & $11: 00-11: 40$ & 10 & 4 items & 3 items \\
\hline $\mathrm{F}$ & 33 & $\begin{array}{l}\text { Company } \\
\text { employee }\end{array}$ & $\begin{array}{l}\text { ZARA (Times } \\
\text { square) }\end{array}$ & $12: 30-12: 55$ & 8 & 5 items & 2 items \\
\hline G & 25 & $\begin{array}{l}\text { Company } \\
\text { employee }\end{array}$ & $\begin{array}{l}8 \mathrm{~s} \text { (Times } \\
\text { square) }\end{array}$ & $15: 45-16: 20$ & 10 & 5 items & 1 items \\
\hline $\mathrm{H}$ & 25 & $\begin{array}{l}\text { Company } \\
\text { employee }\end{array}$ & $\begin{array}{l}8 \mathrm{~s} \text { (Times } \\
\text { square) }\end{array}$ & $16: 40-17: 20$ & 10 & 4 items & 2 items \\
\hline
\end{tabular}

Table 2 Questions and sample responses

\begin{tabular}{|c|c|}
\hline Questionnaire & Sample responses \\
\hline Reason for selecting each item & $\begin{array}{l}\text { It looks pretty; it matches my style; it is what I was } \\
\text { looking for }\end{array}$ \\
\hline Reason for trying on the item in the fitting room & $\begin{array}{l}\text { To check if it fits/matches; to gain confirmation; to } \\
\text { enjoy trying out new outfits }\end{array}$ \\
\hline $\begin{array}{l}\text { Other behaviors in the fitting room besides trying } \\
\text { on the item }\end{array}$ & Sharing it with friends; taking photos \\
\hline How you felt in the fitting room & Good; undecided; concerned; disappointed \\
\hline Reason for not buying the item after trying it on & No sample response was given \\
\hline Whether you look at other people at the fitting room & No sample response was given \\
\hline Opinions on the fitting room environment of the store & Atmosphere, salesperson, mirror, lighting \\
\hline
\end{tabular}

responses were given when participants misunderstood the intention of the question and asked for clarification, as follows.

To analyze the data, the researcher wrote down the observations in field notes and recorded the entire interview with a voice recorder. Then, the researcher transcribed the interview.

\section{Data analysis}

The data were analyzed using open coding, axis coding, and selective coding methods. The researcher performed open coding on the contents of the interviews line by line. Open coding is the process of identifying relevant concepts from the data, then dividing the concepts into subcategories based on their commonalities and differences (Strauss and Corbin 1997). The axis coding refers to the process of reassembling the original data which were divided and disassembled in the process of open coding, and reconnecting 
with the subcategories which are formed in the open coding process to build the frame of the paradigm. The selective coding refers to the process of selecting a central or core category among the categories which were formed during the axis coding, connecting it to the other categories, and elaborating it into a theory (Yoo et al. 2012). The researcher conducted the axis coding and the selective coding simultaneously, followed by selecting the main phenomena from what happened in the fitting room, and creating a paradigm by deriving the inter-category causal conditions, intervening conditions, contextual conditions, actions or interactions, and consequences.

\section{Results and discussion}

\section{Categorizing fitting-room behavior}

The researcher identified concepts by interpreting the participants' shopping behaviors and the contents of the interviews line by line. The researcher clustered similar concepts into a subcategory, and categorized the subcategories according to their attributes. Table 3 presents the categories of the consumer experience while using the fitting room, which were derived via open coding.

Customers have four major concerns when they use a fitting room in a big SPA store. First, they inspect out an item's physical and aesthetic aspects. Consumers used a fitting room to investigate whether the products met their expectations. Secondly, they decide whether to buy an item based on the price and when they might use it. They sometimes ask for advice from friends who accompany them or from other acquaintances through online interactions. Thirdly, and remarkably, consumers try on clothes simply for entertainment. The researcher found that for fashion shoppers, trying on clothes is an opportunity to have "a pleasant experience trying on pretty clothes (Participant C, G)" and to experience "the enjoyable process of discovering what kind of outfits match my taste (Participant B)". Fourthly, the researcher also found that consumers explore other shopper' choices around the fitting room especially when they are waiting to use the fitting room for a long time. They were looking for style information from other shoppers' taste.

\section{The paradigm of trying on clothes}

The raw data broken down in the open coding process were recombined in the axis and selective coding process to reorganize their relationships. The researcher used axis coding to derive main phenomena, causal conditions, contextual conditions, intervening conditions, actions or interactions, and consequences between the concepts and categories.

\section{Main phenomenon}

The researcher categorized consumer behavior in the fitting room into two main phenomena: (1) physically inspecting outfits in terms of size, style, material, and figure; and (2) experiencing emotional pleasure by wearing aesthetically appealing clothes. Unlike previous studies that mainly focused on the element of inspection in the fitting room, this study identified the pleasurable aspect of "trying on clothing" as a notable part of the experience.

As previous studies suggested (Brown and Rice 1998), most participants stated "physical inspection" as their first reason for using the fitting room. It is not difficult to assume 
Table 3 Consumer experience in the fitting room

\begin{tabular}{|c|c|c|}
\hline Category & Subcategory & Concept \\
\hline \multirow[t]{2}{*}{$\begin{array}{l}\text { Inspecting fit and match } \\
\text { with personal taste }\end{array}$} & Inspecting size and fit & $\begin{array}{l}\text { Inspecting the size and fit (Participant A-E): } \\
\text { "I try on items in the fitting room to find } \\
\text { clothes that match well with my body } \\
\text { shape (Participant A)" } \\
\text { "I prefer tapered skirts. I did not buy the } \\
\text { silhouette I desired when I tried on the } \\
\text { item (Participant D)" }\end{array}$ \\
\hline & Inspecting style and taste match & $\begin{array}{l}\text { "I try on clothes to inspect whether the new } \\
\text { vogue style matches my taste (Participant } \\
\text { B, C)" } \\
\text { "I usually try on three or four outfits, but it } \\
\text { is often the case that they do not match } \\
\text { my style as well as I thought they would. } \\
\text { (Participant H)" } \\
\text { "I tried on flower-printed light and supple } \\
\text { clothes many times because I love to } \\
\text { have that feather-like feel and look, but } \\
\text { every time, they did not match my style } \\
\text { at all. I have given up on this challenge, } \\
\text { but of course I might give into charm } \\
\text { while trying on clothes (Participant A)" }\end{array}$ \\
\hline \multirow[t]{2}{*}{ Purchases and decision-making } & Asking for advice & $\begin{array}{l}\text { "I usually ask those who happen to accom- } \\
\text { pany me to tell me what they think } \\
\text { (Participant A, D, H)" } \\
\text { "I ask them even though I like the outfit, } \\
\text { just to inspect if others see what I see } \\
\text { (Participant B)" } \\
\text { "If I really like an outfit, I decide to buy it } \\
\text { without asking others (Participant F, G)" } \\
\text { "If I cannot decide easily, I ask my friends } \\
\text { who come with me, or I take a picture in } \\
\text { the fitting room and send it to my boy- } \\
\text { friend to get his opinion (Participant H)" }\end{array}$ \\
\hline & Deciding whether to buy an item & $\begin{array}{l}\text { "I was afraid that it would look too wide, } \\
\text { and it really did. So I did not buy it } \\
\text { (Participant D)" } \\
\text { "I cannot buy the items all, so I narrow } \\
\text { down my purchase to just one or two } \\
\text { things (Participant E)" } \\
\text { "I try on the outfits that look pretty, but } \\
\text { price seems to be the most important } \\
\text { factor when deciding whether to buy } \\
\text { something (Participant C, G)" } \\
\text { "I tried on the clothes because I desire them } \\
\text { all, but in the end, I think hard about if } \\
\text { they are worth the price and whether I } \\
\text { will really wear them often (Participant } \\
\text { E, F)" }\end{array}$ \\
\hline \multirow[t]{2}{*}{ Enjoyment } & Aesthetic appeal & $\begin{array}{l}\text { "Trying on clothes has its own attraction } \\
\text { (Participant E, H)" } \\
\text { "Trying on new clothes is a new experience } \\
\text { in itself (Participant B)" } \\
\text { "First, I choose pretty clothes without think- } \\
\text { ing too much about whether they fit and } \\
\text { match my style, or if I'll have occasions to } \\
\text { wear them (Participant G)" } \\
\text { "I try on clothes that are not my usual style } \\
\text { or that I wouldn't dare wear. It's just for } \\
\text { fun, because they look pretty. Nobody } \\
\text { cares anyway (Participant C)" }\end{array}$ \\
\hline & Interactions with friends & $\begin{array}{l}\text { "I tend to try new things when friends are } \\
\text { around or when I'm in a comfortable } \\
\text { environment. Today I was a little daring } \\
\text { because a friend was with me. Otherwise, } \\
\text { I would not have attempted to try on } \\
\text { what I did (Participant A)" }\end{array}$ \\
\hline
\end{tabular}


Table 3 continued

\begin{tabular}{|c|c|c|}
\hline Category & Subcategory & Concept \\
\hline \multirow[t]{2}{*}{ Information seekers } & Choices of other shoppers & $\begin{array}{l}\text { "While standing in line, I inspect the clothes } \\
\text { others are holding or the outfits they try } \\
\text { on. I inspect out the clothes I think are } \\
\text { pretty before I leave the store. I look espe- } \\
\text { cially closely at the clothes that refined } \\
\text { and elegant women are holding or have } \\
\text { tried on (Participant F)" } \\
\text { "While standing in line, I look at the clothes } \\
\text { others are holding. If someone is holding } \\
\text { the same clothes as me, I feel uneasy, and } \\
\text { worrying that too many people might } \\
\text { wear them (Participant E)" }\end{array}$ \\
\hline & Hanger items & $\begin{array}{l}\text { "I often take a look at the hanger items } \\
\text { when entering and leaving the fitting } \\
\text { room, out of curiosity at which items sell } \\
\text { well (Participant B)" }\end{array}$ \\
\hline
\end{tabular}

that this reasoning would be more important if they have purchase intention, and in this case, advice from others could be more useful to make decision.

On the other hand, the participants had different opinions as to whether trying on clothes in the fitting room is emotionally pleasant. The following responses reflect the opinion that trying on clothes is cumbersome, and that consumers avoid doing so if they do not intend to purchase an item.

"I feel freer to try on clothes in SPA stores than in department stores where sales assistants are around, but I do not try things on for fun. It is not so pleasant (Participant F)."

"I like shopping, but trying on clothes is not always pleasant. You have to be careful not to get make-up on the clothes, and it is especially cumbersome in winter because there are many clothes to take off and put on again. I only try on the items I want to buy, not the things I am unsure of (Participant E)."

"I usually do not try things on that I do not want to buy. I don't like looking at myself when I wear clothes that do not match my taste well. I avoid trying on clothes unless they are pretty. As I get older, I have a better idea of the types of clothes that fit me well. When I was younger, I used to try on many different styles and even tried to match my taste to my clothes, but I rarely do that now (Participant A)."

At the same time, seven of the eight participants ('Participant A' was exceptional) said that trying on pretty clothes was a pleasant experience in itself. This suggests that customers experience two emotions, cumbersome and enjoyment, simultaneously. Of course, for some customers, fitting means one of two separate experiences: inspection or entertainment.

Although they gave answers ranging from "It can be annoying, but it can also be pleasant (Participant E)" to "very enjoyable (Participant C, G)," it was apparent that they enjoyed trying on the items.

"If I feel like wearing a one-piece dress, I try one. When it looks like I imagined, I love the experience itself. If I really like the item, I buy it. (Participant C)." 
"I try on all clothes I find pretty. I rarely think that trying on clothes is annoying because I really like fashion items. Even if I know I won't buy them, I choose pretty clothes and go to the fitting room to try them on. Trying them on is interesting and makes me happy (Participant G)."

"It is interesting because I get to learn which clothes match my style, and I really enjoy the experience of trying on new items (Participant B)."

As indicated by some of the answers, enjoyment could be interpreted as "a process of learning which fashion styles match my taste".

Next, the author selects the main phenomenon as "Trying on clothes is enjoyable" which is unexpectedly frequent and varying response, and attempt to examine the causes and contexts behind this phenomenon. Main phenomenon represents the study's central theme as interpretations of the participant's features or notable issues relating to the participant (Yoo et al. 2012).

\section{Causal condition}

The researcher assumes that the extent to which the main phenomena occur depend on the intention to buy an item or lack thereof. In terms of the causal condition, the researcher proposed that if the reason for shopping is to "purchase" an item, shoppers place more emphasis on "product inspection," and if the reason is "leisure," they will experience the "pleasure of trying it on" more intensively.

The researcher inferred that shopping for leisure is becoming more widespread than shopping simply to buy, based on the responses of most participants. For example, the "expectation of discovering something pretty, whatever it might be (Participant B, C, G, H)" or "frequent, small shopping sprees for leisure, because it is difficult to find suitable clothes when I urgently need them (Participant D, E, F)". Given that most respondents said they enjoyed trying on clothes, the researcher assumed these two aspects are positively linked.

\section{Contextual condition}

In terms of the contextual conditions for experiencing the "pleasure of trying on clothes," the researcher proposed that SPA stores have a specific atmosphere, which is different from that of conventional department stores. SPA stores have a wide variety of products and present a liberal, independent atmosphere in the fitting room. The following responses supported the hypothesis that SPA stores create conditions for making it enjoyable to try on clothes.

"Because the store is spacious and has a wide variety of products, I come more frequently and stay longer (Participant F)."

"Places such as Forever 21 in Myungdong have floors full of different styles of clothes that won't end. Once I am there, I forget how time passes because it's so interesting everywhere (Participant G)."

"In such places [SPA stores], sales assistants let me look around freely and there is no lack of pretty clothes. So I come frequently and try on many clothes, and finally, I buy more (Participant E)." 
"I go there frequently because there are no time constraints for using the fitting room and Ifeel free in the liberal environment (Participant C)."

\section{Action and interaction}

Regarding actions and interactions concerning the items the participants tried on, we can also consider interactions with family, friends, or other people. In terms of evaluating clothes and deciding whether to buy them, previous studies mentioned heeding the advice of sales assistants or those who accompanied participants as important. In this study, participants also considered the advice of those who accompanied them to be important.

"If someone is accompanying me, I show them myself with the clothing on and ask for his or her opinion (Participant C)."

"Even if I think that the clothes look nice on me, I ask the people who accompany me to inspect whether they see what I see (Participant B)."

"If my boyfriend says 'pretty' or 'not so pretty', it's a lot easier to decide (Participant E)"

Some participants sought the advice of friends online:

"If I find an item to be nice but cannot decide, I take a photo of myself with my smartphone and send it to my friends to ask for their opinions (Participant B)."

"I do not need others' opinions on the clothes that I really like. In case I am not $100 \%$ sure, I ask my friends who are with me, or I take a picture in the fitting room and send it to my boyfriend to ask his opinion (Participant $H)$."

One such response, "I take pictures just to enjoy by myself or show to my friends (Participant G)," demonstrates the aspect of "sharing" an image rather than seeking advice or judgment. Based on the following answers - which express an aversion to showing oneself with unfitting or unflattering clothes, and wishes to have a mirror in the fitting room-we could assume that the intention to share pictures with friends is limited to flattering, well-fitting clothes.

"The presence of a mirror in the fitting room is a big, favorable difference. In department store stands, fitting rooms do not have mirrors and you have to come out of the fitting room after trying on an item to look in the mirror. It's quite annoying that people in the store can look at me when I'm wearing something that might not fit me well (Participant B)."

"There is no mirror in the fitting room, and you have to leave the fitting room to look in the big mirror outside. It's embarrassing and annoying that others could see me. I myself look at others stealthily when they come out of the fitting room. I feel really ashamed, especially if the item makes me look fat or awkward (Participant F)." 
The "entertaining" process of trying on clothing in SPA stores seems to reflect the "disturber" role played by sales assistants in conventional stores. One participant said that the advice of sales assistants might help, yet remarkably, most participants seemed unfriendly toward them. When answering questions to sales assistants, they used negative expressions such as "No thanks (Participant C)," "I feel watched (Participant G)," "burdensome (Participant H)," "I feel hurried (Participant E)," "I have no confidence (Participant E)," or "I feel like they're watching me (Participant B)." One of them even said, "I have a friend that leaves the store quite upset if a sales assistant approaches (Participant G)." Thus, they held very negative views of sales assistants.

The researcher assumed this phenomenon becomes more apparent when the reason for shopping is leisure, rather than simply purchasing an item.

\section{Intervening condition}

Some participants said they do not need their friends' advice.

"If friends are around, I show them what I'm wearing and ask for their opinions, but I know myself better and feel freer alone (Participant G)."

"I know by now which clothes fit me well and which ones don't. Shopping alone is no problem because I do not need or want advice (Participant F)."

Such responses led the researcher to assume that the intervening condition is the degree of confidence a consumer has about fashion items. Those who are very confident do not need or want advice from others.

\section{Consequence}

After or while trying on an item, functional aspects and price seem to influence the consumer's decision to purchase it, in addition to physical and aesthetic standards. Most participants said they strongly intended to buy an item before trying it on, but only bought some of the items they tried. This implies that multiple factors relating to judgment influenced their decision. This also suggests that the factors affecting a purchasing differ depending on whether the reason for trying an item is inspection or pleasure.

The behavior of "just trying on clothes without any intention of purchasing them" might not be regarded as conducive to sales. However, as mentioned earlier, SPA stores that "have many pretty clothes and a comfortable, free atmosphere" entice consumers to visit "more frequently, try on more clothes, and ultimately buy more." This suggests that the environment of SPA stores positively affects sales.

Figure 1 is a flow chart representing the phenomena described above and the intercondition paradigm.

\section{Conclusion}

This study used grounded theory to explore consumer experiences in independent, liberal fitting rooms in SPA stores. Customers carry out four major actions when using fitting rooms in SPA stores.

Firstly, shoppers inspect the physical and aesthetic aspects of the clothing items, which is predictable based on earlier studies. Although the participants of this study responded 


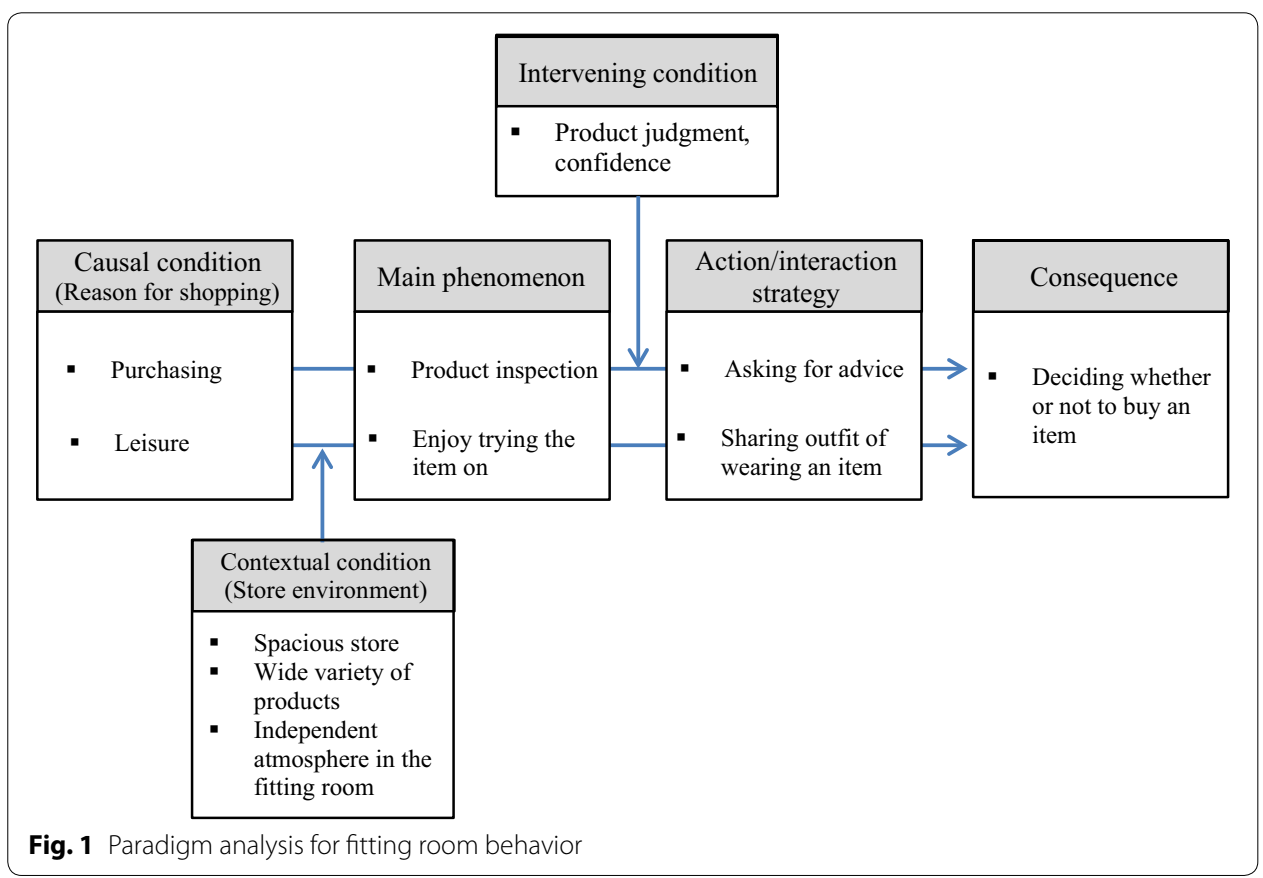

that inspecting the physical aspects was most important, a new finding of the present study shows that there is abundant responses about and detailed descriptions of inspecting aesthetic aspects such as "what will I look like if I wear this style of clothing?". It appears that follow-up studies should focus on whether the independent fitting room environment promotes consumers' aesthetic trials and experiences.

Secondly, the purchase decision is influenced by the advice of the people who accompany them or friends via online interactions, as well as the price and the item's function. Interactions with acquaintance revealed new patterns. Participants regarded advice from sales assistants as not very reliable and rather burdensome. Instead, participants demonstrated that they seek family members or friends' advice online using mobile technology, and by sharing pictures with friends via social networking sites (SNS).

Thirdly, consumers are simply enjoying trying them on as a form of entertainment. We can interpret the fact that consumers have started seeing trying on clothes as a pleasant experience as a new discovery about the function of trying on, which consumers used to consider a "cumbersome and annoying event" they had to go through to figure out an item's physical, functional, and aesthetic aspects. To understand this new phenomenon better, the researcher performed a paradigm analysis. The researcher select "enjoying trying on clothes" as a main phenomenon of this study, and aimed to identify the conditions that affect the main phenomenon using the axis coding method. The results led to the assumption that the pleasure of trying on clothes can be experienced more readily when the reason for shopping is simply leisure. The researcher determined that the process of enjoying trying on items was a form of entertainment, enabled by the spacious store and wide variety of products, as well as the liberal, independent atmosphere in the fitting room.

Finally, consumers explore other shopper' choices while they are using the fitting room or when they are waiting in long line to use the fitting room. Observing the clothing 
items that other consumers are holding or trying on in the fitting room, as well as the hanging clothes items picked out and tried on by other consumers, can be interpreted as a source of real information for seeking new trends.

The marketing insights gained from the study results can be summarized as follows: In today's fashion market, shopping for leisure is becoming increasingly common. Consumers' loyalty can be enhanced by helping them experience the pleasure of exploring and trying on clothes in a pleasant atmosphere. The researcher confirmed that participants thought sales assistants "spoiled" their enjoyment of trying on clothes. This suggests that by minimizing the role of staffs to working at the management level, operation costs can be reduced and consumers' unrestricted shopping sprees can be enhanced.

At an exploratory level of study on a topic that has rarely been addressed in fashion retail studies, the present study intended to explore consumer experiences in fitting rooms. Previous studies on fitting rooms (Kang 2015; Song et al. 2013) focused mainly on the elements of the physical environment such the size of the fitting room, the mirror, or the lighting, and consumers' responses to these elements. This study addressed unrestricted human environments in which fitting rooms comprise many divided sections and a limited role of salespersons; as a result, the new fitting room environment, liberating consumers from other people's eyes, was analyzed as promoting consumers' aesthetic or hedonic trial of fashion items.

This study was limited because the sample population was limited in terms of the region and ages of the participants. Moreover, despite the researcher's efforts to objectively analyze and interpret the data, we cannot rule out process-related errors (such as missed content or subjective interpretations). Therefore, further research is necessary to quantitatively analyze the paradigm derived in this study. An in-depth study on cognitive and emotional aspects could be conducted regarding the process of deciding whether to purchase an item. Moreover, scholars could explore the changes consumers might experience after trying on clothes in terms of emotions, attitudes, and purchase intention.

Received: 13 July 2015 Accepted: 2 September 2015

Published online: 09 November 2015

References

Babin, B. J., Darden, W. R., \& Griffin, M. (1994). Work and/or fun: measuring hedonic and utilitarian shopping value. Journal of consumer research, 20(4), 644-656

Bäckström, K. (2011). Shopping as leisure: an exploration of manifoldness and dynamics in consumers shopping experiences. Journal of Retailing and Consumer Services, 18(3), 200-209.

Baumstarck, A., \& Park, N. K. (2010). The effects of dressing room lighting on consumers' perceptions of self and environment. Journal of Interior Design, 35(2), 37-49.

Bertrandias, L., \& Goldsmith, R. E. (2006). Some psychological motivations for fashion opinion leadership and fashion opinion seeking. Journal of Fashion Marketing and Management: An International Journal, 10(1), 25-40.

Brown, P., \& Rice, J. (1998). Ready-to-wear apparel analysis (2nd ed.). Upper Saddle River: Prentice-Hall.

Choi, K. A., \& Chung, S. J. (2008). Roles of apparel shop managers. Design Forum, 21(11), 1-15.

Cialdini, R. B., Kallgren, C. A., \& Reno, R. R. (1991). A focus theory of normative conduct: a theoretical refinement and reevaluation of the role of norms in human behavior. Advances in experimental social psychology (Vol. 24, pp. 201-234). San Diego: Academic Press.

Cialdini, R. B., \& Trost, M. R. (1998). Social influence: social norms, conformity, and compliance. In D. T. Gilbert, S. T. Fiske, \& G. Lindzey (Eds.), The hand book of social psychology (4th ed., Vol. 2, pp. 151-192). New York: McGraw-Hill.

Fiore, A. M., \& Kimle, P. A. (1997). Understanding aesthetics for the merchandising and design professional. New York: Fairchild.

Howard, E. (2007). New shopping centres: is leisure the answer? International Journal of Retail and Distribution Management, 35(8), 661-672. 
Kang, H. J. (2015). The effect of flattering fitting room environment on purchasing behavior. Unpublished master dissertation. Seoul: Seoul National University.

Kim, M. Y. (1992). A study on change of clothing evaluative criteria according to clothing buying process. Journal of the Korean Society of Clothing and Textiles, 16(3), 367-380.

Kim, H., Choo, H. J., \& Yoon, N. (2013). The motivational drivers of fast fashion avoidance. Journal of Fashion Marketing and Management: An International Journal, 17(2), 243-260.

Kim, H. S., \& Kim, J.Y. (2015). The characteristics of fitting rooms design in outdoor brand store. Journal of Digital Design, 15(1), 275-286.

Kim, K. R., \& Yang, S. J. (2015). Exploratory study on the success factors of SPA brands from marketing perspectives: based on grounded theory. Journal of the Korean Society of Clothing and Textiles, 39(2), 190-203.

Kotler, P., \& Keller, K. L. (2009). Framework for marketing management (4th ed.). New Jersey: Pearson/Prentice Hall.

Kwon, S. Y. (2006). The qualitative study of the consumer experience in clothing retail. Unpublished master dissertation. Pusan: Pukyung National University.

Lee, H. I., Kim, M. S., \& Lee, S. S. (1994). Consumers' purchase tendency and the importance of salespersons' role at the department store. Journal of Korean Home Management Association, 12(2), 26-40.

Moody, W., Kinderman, P., \& Sinha, P. (2010). An exploratory study: relationships between trying on clothing, mood, emotion, personality and clothing preference. Journal of Fashion Marketing and Management: An International Journal, 14(1), 161-179.

Park, J. O., \& Park, H. S. (1995). A study on the consumer's clothing purchasing behavior related to the level of apparel product involvement. The Journal of Korean Living Science Research, 13, 181-207.

Siben, W. A. (1991). An interdisciplinary concept of apparel quality, special publication (Vol. 4, pp. 65-73). Citrus Heights: International Textile and Apparel Association.

Song, H. J., Yang, H. J., Kim, N. H., \& Kim, J. Y. (2013). Analyzing the emotional design factors in SPA brand store: focusing on the SPA fitting rooms in Myeong-dong. Korean Institute of Interior Design Journal, 15(1), 180-185.

Strauss, A., \& Corbin, J. (1997). Grounded theory in practice. Beverly Hills: Sage.

Unger, L. S., \& Kernan, J. B. (1983). On the meaning of leisure: an investigation of some determinants of the subjective experience. Journal of Consumer Research, 9(4), 381-392

Yoo, K. W., Jeong, J. W., Kim, Y. S., \& Kim, H. B. (2012). Qualitative research methods. Seoul: Pakyoungsa.

Yoon, E., \& Kijewski, V. (1997). Dynamics of the relationship between product features, quality evaluation and pricing. Pricing Strategy and Practice, 5(2), 45-60.

\section{Submit your manuscript to a SpringerOpen ${ }^{\circ}$ journal and benefit from:}

- Convenient online submission

- Rigorous peer review

- Immediate publication on acceptance

- Open access: articles freely available online

- High visibility within the field

- Retaining the copyright to your article

Submit your next manuscript at $\boldsymbol{s p r i n g e r o p e n . c o m ~}$ 